\title{
Preparing Industrial Revolution 4.0 (IR 4.0) Ready Graduates
}

\section{Authors:}

1. Dr. Hemlata Vivek Gaikwad, Associate Professor and Head, Department of Management Studies, Rajarambapu Institute of Technology email- hemlata.gaikwad@ ritindia.edu

2. Dr.Sushma Shekhar Kulkarni, Director, Rajarambapu Institute of Technology email-sushma.kulkarni@ ritindia.edu

\begin{abstract}
Industrial revolution 4.0 is characterized with use of cyber - physical systems to automate, monitor and analyze business. The students have access to volumes of information available a click away. Developing the graduates with the futuristic skills is a major challenge in front of educators. The case discusses the pro-activeness of Rajarambapu Institute of Technology (RIT) such as designing innovative teaching strategies, preparing faculties and students and developing smart infrastructure in responding to the changing needs of the industries. At RIT, the challenges are even more intensified as most of the students are first generation learners belonging to farmers' families. Team RIT worked with a belief that together they can bring the change. The study concludes that a triangular systems approach can help the institutes transform and develop the IR4 ready graduates. The three pillars i.e. Management \& faculty, industry and learning systems should be inextricably intertwined with only student as the focus to achieve the expected outcomes. The findings will also prove to be an initial source of reference for other engineering institutes to bring in the educational transformations. Although Industry 4.0 is the buzzword, very few technical institutes understand and realize the concept in detail. This case study will help technical institutes to identify the factors which they have to asses critically and act upon for preparing graduates with futuristic skills.
\end{abstract}

Keywords : Professional Education, Industrial revolution 4.0, Teaching Pedagogy, RIT

Dr. Hemlata Vivek Gaikwad, Associate Professor and Head, Department of Management Studies, Rajarambapu Institute of Technology emailhemlata.gaikwad@ritindia.edu

\section{Introduction}

From the first industrial revolution at the end of eighteenth century, which started with the use of water and steam engines, the world consistently moved through second and then third industrial revolution. The world is now in fourth industrial revolution (IR4.0) is complementing what started in third by enhancing it with artificially intelligent autonomous systems. In simple words, Industry 4.0 is optimization of Industry 3.0 as the basic difference is that in Industry 4.0 , the machines work autonomously without the intervention of a human , whereas in the industry 3.0 the machines were only automatized with a need of human intervention .Now as the future of industry 4.0 is unfolding everything and everyone is networked. Internet of things, clouds, 3D printing, robotics etc. had become the buzzwords suddenly. Companies who have adopted are realizing the potential of IR4.0 are upskilling their workforce and recruiting new employees with the right skills. One of the important point is the impact of IR4.0 on employment. IR4.0 will bring higher level of automation and interconnectivity in industrial processes. The tools, technologies and skills required to handle them are expected to be different from what they are at present. New job opportunities that will emerge includes Artificial Intelligence, Robotics, 3D printing, Digital marketing, Cyber Security Specialists so on and so forth. But for shaping students for this new world, we need a planned and systematic approach and collaboration across sectors. This also requires a major overhauling of Indian higher education specifically technical educational institutes. This has put forth new challenges in front of educators of institutes imparting professional education. Some of these challenges include Training and Continuing Professional Development as priority areas for actions within industry 4.0 implementation (Kagermann, Helbig, Hellinger, \& Wahlster 2013, Engineer 2020), need of New learning approaches (Abele et al., 2015, Engineer 2020) and developing Strong Skills in Human Relations (Male, Bush \& Chapman 2010).According to a survey conducted by Deloitte ( 2019) $60 \%$ of the students surveyed responded that their college or university did not prepare them for the job they want and $79 \%$ of them 
reflected that they had to go outside of formal college for learning the required skills. In view of readiness for the IR 4.0 workplace, the management wondered - What could be the skills we need to develop in our students to keep up the pace ? Do our graduates understand IR 4.0 and its impact on the future workforce requirements? Are they aware of the skills this industry is looking for? Are they prepared for this ever evolving and dynamic digital workplace? To explore answers to these questions we captured the experiences of the management and faculty of Rajarambapu Institute of Technology, an emerging leader in Maharashtra.

\section{Methods}

The study is based on content analysis of secondary data. The data was collected from the institutional websites, news paper reports, magazine articles, review comments on social media websites, annual reports for NAAC and NBA. The documents and reports were manually screened and analyzed by the authors. To confirm the reliability and validity the questions stated by Stewart \& Kamins (1993) were focused.

\section{Findings}

Realizing the needs of IR4.0, the management and senior faculty members at Rajarambapu Institute of Technology (RIT) initiated steps in the direction to find answers to these questions. RIT is a wellknown Technical Institute in the Western Maharashtra. It is an integrated campus offering undergraduate and postgraduate programs in engineering and management. It is in a rural township where most of the students are first generation learners coming from farmers' families. They are fully reliant on their academic curriculum and faculty to make them job ready. The faculty started with evaluating and assessing the curriculum to find its effectiveness in providing the right exposure and real-world insights to the students preparing to enter the workforce and to find what they need to add and scale up besides improving academic curriculum. The initiatives discussed below had started the process of equipping future talents for this ever-evolving technological workplace.

Some of these initiatives were designed keeping in view the six IR 4.0 building blocks (Kirchner, 2017) and changes expected in education (Lodder ,2016) .
There were three major areas in which Team RIT worked viz. Connecting Curricula and Industrial Success Skills, Developing students and Faculty 4.0 and Smart Infrastructure. These initiatives were also aligned with and incorporated in the strategic plan of RIT. The strategic plan at RIT is developed as per the One Page Strategic Plan (OPSP), a simple but powerful tool developed by Verne Harnish which kept all stakeholders on the same page literally and figuratively. It also helped in achieving desired results by bringing better alignment, execution and accountability.

\section{Initiative 1: Connecting Curricula and Industrial Success Skills}

According to a report published by McKinsey Global Institute based on an analysis of 750 occupations, $51 \%$ of the job activities will get automated, making many of the current skills redundant. Hence, to prepare graduates for the workplace of future, it was important to identify the skillset and to incorporate futuristic courses in curriculum. The department advisory board members visited many industries in major industrial areas in Maharashtra, conducted video conference calls with various company officials in India and held discussions with the Deans in Universities abroad through our global connect with GEDC, IFEES, IUCEE, ISTD and ISTE. The inputs received were brainstormed at department levels first and then were discussed in the steering committee of the institute. The skill sets which needed to be developed for making graduates IR 4.0 ready were compiled. The curriculum revamping was the next step. The following were the major changes incorporated:

1. Introduction of multidisciplinary electives

2. Major and Minor Specializations

3. Interdisciplinary projects

4. Blended learning modules

5. Life skill development courses for students and faculties

6. Credit transfers from courses taken from other universities or industries.

7. Value added industry recognized advanced certifications

8. Compulsory soft skill courses for professional development

9. Certification in Foreign Languages like Japanese and German

RIT's Response Initiatives 
10. Introduction of machine learning languages, big data processing and coding for all programs

As today's learners are tech savvy, they want to engage in learning processes through multiple modes as per their convenience and pace. Hence, our curricular content is made available through multiple modes -Blended (Through MOODLE and MHRD collaborations), Online ( MOOCs) and on campus learning.

As sensitivity to society was one important skill, community-based projects were introduced in all programs. We adopted nearby villages, worked with local government and successfully provided technical solutions to their problems. To illustrate a major project, we worked with Islampur municipal council in developing smart city Islampur planning aiming at sustainable development.

The elements of humanities and arts are also introduced in the curriculum to make our students capable of handling human-machines interactions.

We had developed strong connect with around 400 industries which supported us in designing a dynamic curriculum to impart the future technical competencies in graduates. The quality and standard of curriculum was reflected when experts from AICTE, NBA committees and various other government bodies gave positive feedback regarding the connectivity of curriculum with required futuristic skills. As a process, we regularly take feedback from our employers and officials of top MNCs appreciated the learnability and adaptability of our alumni and the passing out graduates.

To quote an HR of Big Retail House "I was considering Amit( Pseudo name) as a fresher, but to my surprise, within two months he has created such an image among his team and customers that all our customers come to us asking about him. He has excellent learning and communication skills."

We also conduct alumni survey on curricular aspects. The average rating provided by the alumni on the relevance of curriculum pertaining to current and future skills required by industry is above 9 out of a ten point rating scale every year.

Initiative 2 : Developing students and Educators 4.0
"65\% of children entering primary school today will ultimately end up working in completely new job types that don't yet exist.." (World Economic Forum, 2016)

It was quite apparent that student should be central to education to prepare them for jobs that don't exist yet.

All the efforts like curriculum design and reforms, pedagogy, trainings (In-house and industrial), evaluations design should focus on developing the student for future workplace. The most important attributes which must be developed in students are Innovative \& Growth mindset, Creativity, Emotional intelligence, Interdisciplinary collaboration, Cognitive Flexibility, Algorithm and logic etc. Once the student enters their professional career, they will need to apply these skills and to impart them we need creative educators. Our brainstorming revealed two aspects:

- Educators and students need to change mindset

- $\quad$ Redesigning teaching

We understood that preparing students 4.0 will need changing mindset of educators, they being the major change makers . The educator's strategy should be to adapt to the changing requirements or perish. Gerstein (2014) stated that educators must move on from fixed mindset to growth mindset which will enable them from feeling powerless and helpless to feeling of empowerment to positively influence the learner's community. We at RIT understood that growth mindset is key to develop educators 4.0. Several workshops were conducted to imbibe growth mindset in faculty. This made the future processes easier. The educators understood that their role is to facilitate learning, they are not knowledge transferrers. Today's students have access to huge information. Apart from instructor led sources, they wish to learn from multiple modes enabling them to learn at their own pace The educators started looking for new approaches to learning. Blended/hybrid learning approaches, innovative teaching methods like inquiry based learning, problem and project based learning became an integrated style of our educators. These approaches helped develop growth mindset among students as well enabling them to become lifelong learners. To put in short, the approach of heutagogy is being used by the educators at RIT, which means they are adopting a student - centered instructional strategy focusing the 
development of capacity, capability and autonomy among students. Winning the awards mentioned below and the placements of the students indicate the success of our efforts.

\section{Initiative 3 : Developing Smart Infrastructure}

The future jobs will be in the new areas like artificial intelligence, Robotics, digital marketing, 3D printing, cyber security and more To Facilitate imparting future skills for such jobs for IR 4.0 a big change in infrastructure was also required. The following actions were undertaken to develop infrastructure:

- All classrooms in the institute are smart with interactive white boards in every department.

- Separate IoT labs by departments of Computer engineering, Information Technology and Electronics and Telecommunication Engineering with different kits from ardino, Intel, Raspberry, controller and Amazon cloud instances are used

- Robotics and drone lab

- Computer graphics and virtual reality labs with opengl and CUDA computing facilities used

- Machine learning/AI lab having python programming with high computing facilities.

- 3D printing lab

- Living Labs: Build an Autonomous Electric Vehicle (AEV) which helped in developing a product based learning framework. (Exhibit I).

- A well-equipped multi storeyed independent Library.

The infrastructure was developed in consultation with industry experts. Most of the laboratories are sponsored by industries. This infrastructure helped impart IR 4.0 skills in graduates to a great extent. They have won several awards at national and international level like

1. RIT's NRiT Dream Team 1\% Secured 1st Rank in COVID-19 Innovation Challenge Organized by Atal Incubation Centre - Sri Krishnadevaraya University AIC-SKU, Andra Pradesh
2. Team Luftwaffe 6.1 (Go-Kart Racing Team) has again grabbed All over India 1st rank in the final round of Go-Kart Racing Championship

3. RIT wins 14th State Level Award for Excellence in Energy Conservation and Management, MEDA Pune

4. RIT is awarded with Best Autonomous Institute with Global vision at the hands of Hon. Vinod Tavade, Education Minister, Govt. of Maharashtra

5. RIT Declared as a "Most Innovative Brand" in Maharashtra by Maharashtracha Lokpriya Brand 2019 (Arthsanket)

6. Team Luftwaffe 5.0 (Go-Kart Racing Championship) has received 1 st rank in final round of Go-Kart Racing Championship. The event was organized by Indian society of New Era of Engineers (ISNEE) and was held at Buddh International Circuit, Noida.

7. TEAM NEQUIT 4.0 has secured ALL INDIA RANK 18 among 126 teams in SUPRA 2018 organized by SAE INDIA and sponsored by Maruti Suzuki.

\section{Conclusion}

"In the new world, it is not the big fish that eats the small fish, it's the fast fish that eats the slow fish"

\section{Klaus Scwab, Founder and Executive Chairman. World Economic Forum}

We at RIT understood that if we delayed our efforts in bringing in the change, our students will not be able to cope up in the new world as, today we are in a situation where we are preparing the graduates for the jobs that don't exist, by using technologies for the future and trying our level best to impart the industry relevant futuristic skills like analytical and problem solving skills for solving problems which are not known yet. Obviously, it is a challenging task for all professional educators and institutes.

The initiatives at RIT discussed above show the efforts team RIT is taking to develop workforce of the future. It is triangle with systems at one end, faculty at another and industry at the third vertex with students as the centre with heutagogy as the process, very similar to the service triangle. 


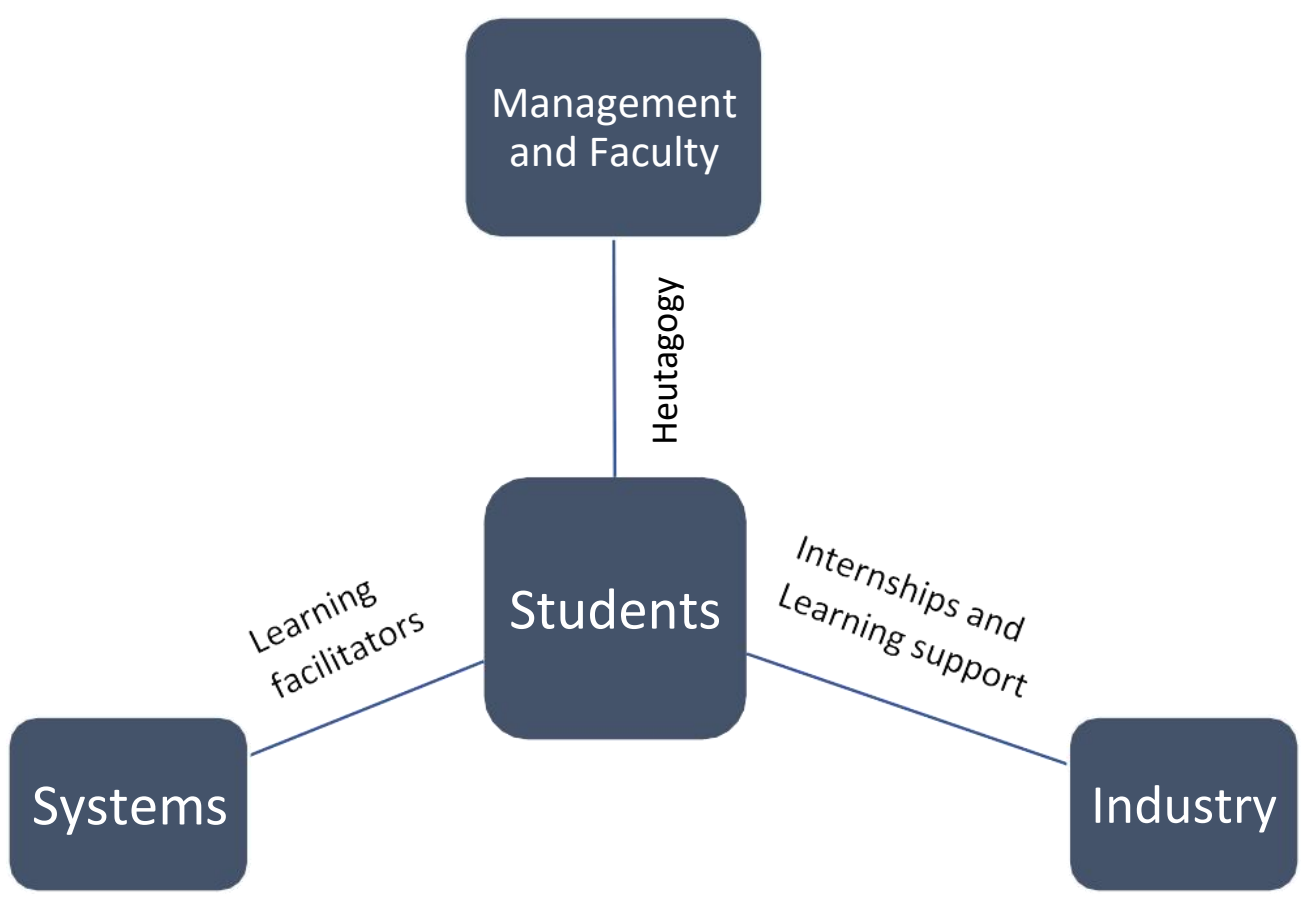

Figure I : The Collaboration Triangle - A systems Approach

In the time where speed is the new currency of business (Marc Benioff, chairman and CEO

,Salesforce), all institutes must take collaborative efforts with industry to develop a workforce for the industrial revolution 4.0 .

The findings of the study can prove to be helpful to other technical institutes to identify the factors which they have to asses critically and act upon for preparing graduates with futuristic skills. It will also serve as the guideline to understand the direction of initiatives needed to sustain in IR4.0.

\section{References:}

1. Kagermann, H., Wahlster,W., Helbig, J.(2 013). Recommendations for implementing the strategic initiative Industrie 4.0. Final report of the Industrie 4.0 Working group

2. Male, Sally \& Bush, M.B. \& Chapman, Elaine. (2010). Perceptions of competency deficiencies in engineering graduates. 16. 55-67.

3. Abele, E., Metternich, J., Tisch, M., Chryssolouris, G., Sihn, W., ElMaraghy, H., Hummel, V., Ranz, F. (2015). Learning Factories for research, education, and training. Key note paper of the 5th International Conference on Learning Factories. Procedia CIRP

4. Gerstein, J. (2014). Moving from Education 1.0 Through Education 2.0 Towards Education 3.0. Experiences in Self-Determined Learning., 83-98. Retrieved from http://scholarworks.boisestate.edu/edtech facpubs/104

5. Kirchner, M. D. (2017). Teaching the Industrial Internet of Things Preparing Students and Learners for Industry 4.0, (September), 0-17.

6. Lodder, J. (2016). The Fourth Industrial Revolution and the Education System, how to respond? Retrieved from. https://www.linkedin.com/pulse/fourthindustrial-revolution-education-systemhow-respond-john-lodder

7. Stewart, D. W., \& Kamins, M. A. (1993). Secondary research: Information sources and methods. Newbury Park, CA: Sage. 
Exhibit I : Autonomous Electric Vehicle (AEV)

project started in RIT in collaboration with NETRA

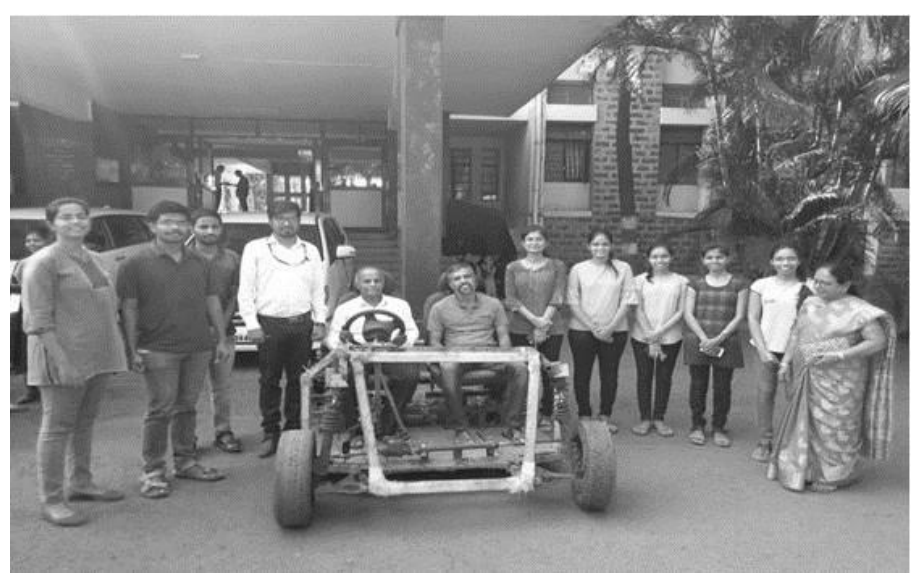

